\title{
Assessment of temperature stability of nanoparticle formulated vinblastine
}

\section{MANAR W. JAN*, ALOK SINGH AND JISHNU NASKAR}

Department of Molecular and Cellular Engineering, Sam Higginbottom Institute of Agriculture, Technology and Sciences, ALLAHABAD (U.P.) INDIA

\section{ARITCLE INFO}

Received : 02.02 .2016

Revised : 06.09.2016

Accepted : 20.09.2016

\section{KEY WORDS :}

Catharanthus roseus, Terpenoid indole alkaloid, Vinblastine, Silver

Nanoparticles, LDH, MMT
*Corresponding author:

Email : jishnu.naskar@shiats.edu.in

\begin{abstract}
Catharanthus roseus L. (Madagascar periwinkle) is regarded as a rich source of pharmaceutically important terpenoid indole alkaloids(TIAs) which are valued highly due to their wide spectrum of pharmaceutical application. Among these, vinblastine and vincristine are of particular importance because of their wide use in cancer chemotherapy. Vinblastine can have extensive use for the treatment of lung cancer, breast cancer, head and neck cancer and testicular cancer. It is also used to treat Langerhens cell histocytosis. This study was done to assess the stability of vinblastine. The extracted crude vinblastine was formulated with nanoparticles at different temperature. Stability was determined at varying temperature. Reduction method was used to synthesize silver nanoparticles, LDH was synthesized using co-precipitation method and MMT was purchased from Sigma-Aldrich.LDH and MMT formulated vinblastine showed maximum temperature stability at $60^{\circ} \mathrm{C}$ and $80^{\circ} \mathrm{C}$. The increase in heat stability will help in increasing the shelf-life as well as storage at room temperature, eliminating the need for refrigeration. Study shows that formulation of NP-TIA's has significant potential in drug delivery and enhanced shelf -life and storage condition.
\end{abstract}

How to view point the article : Jan, Manar W., Singh, Alok and Naskar, Jishnu (2016). Assessment of temperature stability of nanoparticle formulated vinblastine. Internat. J. Plant Protec., 9(2) : 556-560, DOI : 10.15740/HAS/IJPP/9.2/556-560. 